\title{
Serum cholinesterase as liver function test in cirrhotic patients at Soba Teaching hospital, Khartoum, Sudan
}

\author{
Nagah A. A. Mohamed ${ }^{1}$, Mohamed Amanullah ${ }^{2 \star}$, Ramazan Amanvermez ${ }^{1}$, Mariam A. Ibrahim ${ }^{3}$ \\ and Moneer Abbas ${ }^{4}$
}

${ }^{1}$ Department of Medical Biochemistry, Faculty of Medicine, Ondokuz Mayis University, KSA.

${ }^{2}$ Department of Clinical Biochemistry, Faculty of Medicine, King Khalid University, KSA.

${ }^{3}$ Department of Clinical Chemistry, Faculty of Medical Laboratory Sciences, Sudan University of Science and Technology, Sudan.

${ }^{4}$ Faculty of Medical Laboratory Sciences, Sudan University of Science and Technology, Sudan.

Accepted 19 July, 2017

\begin{abstract}
It is suggested that plasma cholinesterase level is affected by liver cirrhosis due to hepatocyte injury. The objective of this study was to determine cholinesterase values in association with albumin and prothrombin during both the compensated and decompensated stages in cirrhotic patients. A total of 150 consecutive episodes of liver cirrhotic patients, aged (68.9 \pm 10 years) admitted to the hospital between June 2015 and December 2015 were studied. They were classified into subgroups according to severity and the stages of disease into group A (compensated stage) and group B (decompensated stage), each containing 75 patients. Fifty apparently healthy participants aged $64.5 \pm 13$ years were recruited as controls. Blood samples were drawn and targeted parameters were assessed using commercial kits according to the manufacturer's guide. SPSS package was used for data analysis. There was a significant difference in the mean serum cholinesterase activity, albumin level and prothrombin time of cases and controls. The mean serum cholinesterase value of compensated cirrhotic patients was $3143.83 \pm 1583.44 \mathrm{IU} / \mathrm{L}$ and it was significantly higher $(p=0.000)$ than that of decompensated cirrhotic patients $(1895.32 \pm 531.79 \mathrm{IU} / \mathrm{L})$. There was a strong negative correlation between serum cholinesterase activity and prothrombin time $(r=-0.580, p$ $=0.000)$ and a strong positive correlation between serum cholinesterase activity and albumin concentration $(r=0.617, p=0.00)$. The results conclude that, cholinesterase level reflects liver cell conditions wherein low levels indicate hepatocellular damage. In addition, its levels are stable and not easily affected by medications that are given for cirrhotic patients thus, can be used as a marker for the diagnosis and prognosis of liver damage along with prothrombin time and albumin.
\end{abstract}

Keywords: Cirrhosis, liver function tests, serum cholinesterase, albumin, prothombin time.

*Corresponding author. E-mail: amanullahmohammed@yahoo.com.

\section{INTRODUCTION}

Cirrhosis is a clinical condition wherein blemish tissue replaces normal tissue of the liver. As the healthy liver tissue is replaced by blotted tissue there is an obstruction in the flow of blood through the liver affecting its function. Cirrhosis rarely causes signs and symptoms in its early stages, but as liver function deteriorates, the signs and symptoms appear. Although some patients with cirrhosis may have prolonged survival, they generally have a poor prognosis (Bishop and Edward, 2010). Cirrhosis has two different levels: in the first phase, the liver works nearly normal even though there is mutilation of its cells. This is known as compensated cirrhosis. There may be sparse or minimal symptoms in most of the patients with compensated cirrhosis. In the second phase known as 
decompensated cirrhosis, there is acute liver scarring resulting in disorganized vital function of the body. In such patients, there is an eruption of life-threatening signs, symptoms and complications. Indicators of the onset of decompensated cirrhosis include but are not limited to the sensation of weakness and fatigue, loss of appetite, weight loss, abdominal pain, nausea and emergence of spider angiomas over the skin. Small blood vessels exude from red spots that are pinhead-sized. Fluid buildup in the legs and feet (edema) and in the abdomen (ascites), itching, occasionally reddish and blotchy palms, a condition known as palmar erythema are some of the symptoms that start to develop as cirrhosis progresses to the decompensated stage., swelling of breasts or shrinkage of the testicles may occur in men, as well as easy bruising and excessive bleeding (Lim et al., 2009).

Liver function tests (LFTs) that measure the level of serum liver enzymes usually reflect hepatocyte integrity or cholestasis rather than liver function (Giannini et al., 2005). Five laboratory assays are commonly called liver function tests, although these tests are neither specific to the liver nor true measures of liver function (Titcomb, 2003). Injury to the liver, whether acute or chronic, eventually results in an increase in serum concentrations of aminotransferases; aspartate amino transferase (AST) and alanine amino transferase (ALT) (Dufour et al., 2000; Vanderlinde, 1986). Both aminotransferases are highly concentrated in the liver. AST is also diffusely present in the heart, skeletal muscle, kidneys, brain and red blood cells, while ALT has low concentrations in skeletal muscle and kidney (Rej, 1989). An increase in serum ALT levels is, therefore, more specific for liver damage (Seeto et al., 2000). The half-life in the circulation is about 47 hours for ALT, and about 17 hours for total AST (Dufour et al., 2000). Both enzymes require pyridoxal-5'-phosphate (vitamin $B_{6}$ ) in order to carry out their reactions, although the effect of pyridoxal-5'-phosphate deficiency is greater on ALT activity than on that of AST (Dufour et al., 2000; Vanderlinde, 1986). This has clinical relevance in patients with alcoholic liver disease, in whom pyridoxal-5'phosphate deficiency may decrease serum ALT activity and contribute to an increase in the AST/ALT ratio that is observed in these patients (Pratt and Kaplan, 2000).

Alkaline phosphatase (ALP) is an enzyme that transports metabolites across cell membranes. Liver and bone diseases are the most common causes of pathological elevation of serum ALP levels, although ALP may originate from other tissues, such as, kidneys, intestines, and leukocytes (Fishman, 1990). The third trimester of pregnancy (placenta origin) and adolescence (bone origin) are associated with an isolated increase in serum ALP levels (Dufour et al., 2000). Cholestasis enhances the synthesis and release of ALP, and accumulating bile salts increase its release from the cell surface (Moss, 1997; Schlaeger et al., 1982). In metastatic cancer of the liver, lymphoma or infiltrative diseases such as sarcoidosis, there are abnormal serum ALP levels. Cholestatic pattern may also be seen in druginduced liver injury (a rise in serum ALP or ALT/ALP ratio of $<2$ ), although the degree of ALP alteration is variable and may be accompanied by hyperbilirubinemia. ALP half-life in the circulation is about 1 week. These characteristics explain why ALP levels usually rise late in bile duct obstruction and decrease slowly after resolution. The degree and rate of enzyme alteration may provide minor and nonspecific clues to diagnosis (Velayudham and Farrell, 2003).

A change in serum albumin level or prothrombin time may be associated with a decrease in liver functioning mass, although neither is specific for liver disease (Giannini et al., 2005). Cholinesterase is a family of enzymes that catalyze the hydrolysis of the neurotransmitter acetylcholine into choline and acetic acid. There are two types; Acetylcholinesterase, also known as erythrocyte cholinesterase found on RBCs cell membrane and Pseudocholinesterase, known as plasma cholinesterase, produced in the liver (Wang et al., 2005). Plasma Cholinesterase is synthesized mainly in hepatocytes and is released into the blood (Yanai and Hoshino, 2010). Its activity reduces in liver dysfunction due to reduced synthesis. In contrast to cholinesterase activity, the activities of other serum enzymes associated with the clinical assessment of liver function, increase due to excessive release from their cellular sources after cell membrane damage (Zhou and Tu, 2003).

Alterations in liver enzyme levels that are encountered in hospital centers may vary by the geographical location of the hospital and the ethnicity of the patients (Giannini et al., 2005). Nevertheless, diagnosis may not be evident even after thorough evaluation in asymptomatic patients with mild increases in liver enzymes levels. So this research aimed at investigating the diagnostic and prognostic value serum cholinesterase among Sudanese cirrhotic patients.

\section{MATERIALS AND METHODS}

\section{Study population}

A total of 150 consecutive episodes of liver cirrhotic patients (68.9 \pm 10 years old) admitted to Soba Teaching hospital, Khartoum, Sudan, between June 2015 and December 2015 were studied. They were classified into subgroups according to the severity and the stages of disease into group A (compensated stage) and group $B$ (decompensated stage), each containing 75 patients. All the patients were under treatment for cirrhosis by use of one or the other medication. Fifty apparently healthy participants aged (64.5 \pm 13) years were recruited as the control group.

\section{Ethical consideration}

Ethical clearance was obtained by the local ethical committee before the commencement of the study. The aims and benefits of 
this study were explained to the participants who signed an informed consent. The authors declare that there is no conflict of interest.

\section{Sampling}

Blood sample was collected from each individual for assessment of serum cholinesterase activity according to Ramazan et al. (Amanvermez et al., 2010), serum albumin and prothrombin time (PT) were measured by colorimetery, and a coagulometer respectively using commercial kits from Crescent Company according to the producer's guide.

\section{Statistical analysis}

The data was analyzed using Statistical Package for Social Sciences (SPSS), Windows version 8x, 1997 SPSS, Inc, Chicago, $\mathrm{IL}$, and USA. Independent t-test was used to compare group means. Statistical significance was set at $\mathrm{P} \leq 0.05$.

\section{RESULTS}

As shown in Table 1, there was a significant difference in the prothrombin time, and the mean serum values of cholinesterase and albumin among the case and control groups $(p=0.000)$.

As shown in Table 2, the mean serum cholinesterase value of Group A patients (compensated stage) was significantly higher $(p=0.000)$ when compared to Group $B$ patients (decompensated stage).

There was a strong negative correlation between serum cholinesterase activity and PT $(r=-0.580, p=$ 0.000 ) and a strong positive correlation between serum cholinesterase activity and albumin concentration $(r=$ 0.617, $p=0.00$ ) (Table 3).

The compensated liver cirrhotic patients (group A) showed a strong negative correlation between cholinesterase activity and PT $(r=-0.632, p=0.00)$ and no correlation between cholinesterase activity and albumin concentration (Table 4).

Decompensated liver cirrhotic patients (group B) revealed no correlation between cholinesterase activity and albumin concentration or prothrombin time (Table 5).

\section{DISCUSSION}

Liver diseases are quite prevalent throughout the globe. Their early and correct diagnosis is always a concern among physicians, especially the residual liver function (Tripathi et al., 2015). Liver function test by use of serum enzymes is a good tool but it is usually difficult in screening patients exhibiting or concealing signs of liver disease. The general scientific word "liver function tests" is a misnomer as many tests are used for the diagnosis of damage to hepatocellular cells but not the liver function. True liver function tests are those that measure synthesis of proteins made by the liver (albumin, clotting factors) or the liver's capacity to metabolize drugs. A commonly ordered panel of automated tests includes bilirubin, aminotransferases, alkaline phosphatase, and gamma- glutamyl transpeptidase. This article presents the relationship between liver diseases increase serum levels of various enzymes and their limitation in clinical diagnosis while highlighting a system for assessing abnormal liver test results (Rochling, 2001). A previous study reported that cirrhosis affects the liver and prevents it from functioning properly by diminishing albumin and coagulation proteins synthesis (Bishop and Edward, 2010). The routine use of serum biochemical tests allows for the detection of acute and chronic liver injury before the onset of symptoms. These investigations include, indicators of injury to hepatic cells like aminotransferases and acid phosphatases; total bilirubin as an indicator of liver metabolism; and assays of liver synthetic function of producing serum albumin and Prothombin (Woreta and Alqahtani, 2014). Pseudocholinesterase which is known as plasma cholinesterase, butyrylcholinesterase, is produced in the liver and found primarily in plasma (Wang et al., 2005). Serum or plasma cholinesterase activity is reduced in liver disease.

This study shows that there is a significant decrease in serum cholinesterase cirrhotic patients compared to the control group. This could be as a result of liver cirrhosis that directly affects its function leading to deficient liver production. This is in agreement with findings by Ramachandran et al. (2014). The synthetic function of the liver is reflected by the levels of serum cholinesterase (ChE) which is synthesised by hepatocytes (Matsuzaki et al., 1980; Strahl and Maier, 2006). In liver cirrhosis and hepatoma the array of serum cholinesterase isozyme seemed to be symptomatically elevated. In $92.5 \%$ of 53 patients studied for the diagnosis of liver cirrhosis an irregular fast moving peak was seen. Further, in $58.5 \%$, there were lessening levels of ChE 3 and 4, along with development of weak bands with unusual rates of flow. The pattern in liver cirrhosis was basically the same as that of hepatoma, although in some cases variety of bands was also seen. It was confirmed that these aberrations were due to binding of sialic acid to the enzyme, and not due to abnormal enzyme protein moiety synthesis. They opined upon their clinical trials that diagnosis and prognostic evaluation of liver cirrhosis can be assessed based upon the degree of the abnormality of the isozyme.

This study reveals a mean serum cholinesterase (IU/L) $2519.58 \pm 3.2$ in cases compared to $5984.0 \pm 1.9$ in controls. This is in agreement with a study conducted by Ramachandran et al. (2014) who found median serum ChE in cirrhotics was $1590 \mathrm{IU} / \mathrm{L}$ (110 to 8143) compared to $7886 \mathrm{IU} / \mathrm{L}$ (2022- 21673) in controls. Determining serum albumin levels and assessing prothrombin time are often considered "tests of liver function" (Bonis et al., 1999; Kamath et al., 2001; Kamath et al., 2001). This is primarily due to a decrease in synthesis of albumin by the liver during the end-stage liver disease, and decreased 
Table 1. Estimated biochemical parameters among study participants.

\begin{tabular}{lccc}
\hline Parameter & $\begin{array}{c}\text { Patients (Mean } \pm \text { SD) } \\
\mathbf{n}=\mathbf{1 5 0}\end{array}$ & $\begin{array}{c}\text { Control (Mean } \pm \mathbf{S D} \text { ) } \\
\mathbf{n}=\mathbf{5 0}\end{array}$ & p value \\
\hline Cholinesterase (IU/L) & $2519.58 \pm 3.2$ & $5984.0 \pm 1.9$ & 0.000 \\
Albumin (g/L) & $27.12 \pm 8.27$ & $42.5400 \pm 5.3$ & 0.000 \\
Prothrombin Time (s) & $17.94 \pm 5.47$ & $12.64 \pm 1.55$ & 0.000 \\
\hline
\end{tabular}

Table 2. A comparison of serum cholinesterase activity among liver cirrhotic patients.

\begin{tabular}{lccl}
\hline & $\begin{array}{c}\text { Group A (Mean } \pm \text { SD) } \\
\mathbf{n = 7 5}\end{array}$ & $\begin{array}{c}\text { Group B (Mean } \pm \text { SD) } \\
\mathbf{n = 7 5}\end{array}$ & p value \\
\hline Cholinesterase (IU/L) & $3143.84 \pm 15.83$ & $1895.32 \pm 5.31$ & 0.00 \\
\hline
\end{tabular}

Table 3. Correlation between serum cholinesterase activity and other estimated parameters among study participants.

\begin{tabular}{lcc}
\hline Parameter & Albumin (g/L) & Prothrombin time (s) \\
\hline \multirow{2}{*}{ Cholinesterase $(\mathrm{IU} / \mathrm{L})$} & $\mathrm{r}=0.617^{\star}$ & $\mathrm{r}=-0.58^{\star}$ \\
& $\mathrm{p}=0.00$ & $\mathrm{p}=0.00$ \\
\hline
\end{tabular}

Table 4. Correlation between serum cholinesterase activity and other estimated parameters among compensated liver cirrhotic patients.

\begin{tabular}{lcc}
\hline Parameter & Albumin (g/L) & Prothrombin time (s) \\
\hline \multirow{2}{*}{ Cholinesterase (IU/L) } & $r=0.244$ & $r=-0.632^{*}$ \\
& $p=0.24$ & $p=0.01$ \\
\hline
\end{tabular}

Table 5. Correlation between serum cholinesterase activity and other estimated parameters among decompensated liver cirrhotic patients.

\begin{tabular}{lcc}
\hline Parameter & Albumin $(\mathbf{g} / \mathbf{L})$ & Prothrombin time $(\mathbf{s})$ \\
\hline Cholinesterase & $r=0.124$ & $r=-0.108$ \\
$(\mathrm{IU} / \mathrm{L})$ & $\mathrm{p}=0.954$ & $\mathrm{p}=0.606$ \\
\hline
\end{tabular}

synthesis of liver-derived coagulation factors leading to an increase in prothrombin time. Serum albumin levels and prothrombin time are useful tools for monitoring the synthetic activity of the liver. Thus, albumin levels decrease when cirrhosis occurs, and they have prognostic value in these patients (Green and Flamm, 2002; Dufour et al., 2000; Seeto et al., 2000; Doumas and Peters, 1997). Nevertheless, tests that involve administering exogenous compounds may be used to evaluate liver function more accurately (Dufour et al., 2000). In this study, PT tend to increase significantly and albumin showed low level in cirrhotic patients compared to the controls. Liver disease patients (Saxena et al., 2013) have complex hemostatic defects leading to a delicate, unstable balance between bleeding and thrombosis. Both serum albumin and prothrombin time can be considered useful tools, alone or combined in clinical scores, for evaluating liver function (Bonis et al., 1999; Kamath et al., 2001; Botta et al. 2003). Also Potze et al. (2015) documented preserved clot formation in plasma from patients with cirrhosis, which is in line with the results of the thrombin generation assay in this study previously reported by others.

The serum cholinesterase level tends to decrease significantly among the decompensated group compared to the compensated group. Therefore continuous liver cells damage, leads to a deficiency in the synthesis of cholinesterase enzyme. In agreement with Chen et al. (2011) serum cholinesterase is an excellent biomarker of cirrhosis with good sensitivity and specificity. It shows 
good correlation with serum albumin and PT. Since it distinguishes decompensated cirrhosis from compensated cirrhosis well, low levels in cirrhosis may serve as a useful prognostic marker of advanced liver disease. Serra et al. (2015) recommended that serum creatinine concentration is a parameter that should be included in the prognostic assessment of patients with decompensated cirrhosis, it should be combined with other specific parameters of liver function, such as bilirubin, albumin, and the international normalized ratio (INR) for prothrombin time.

The absence of correlation between serum cholinesterase and PT in the compensated group and cholinesterase and both PT and albumin in the decompensated group, can be explained by the administration of albumin and blood transfusion. These findings provide evidence for a limitation in the use of cholinesterase as a liver function test. This is in agreement with Ramachandran et al. (2014) who found that correlation coefficient between cholinesterase and albumin was -0.67, and Lee (2012) who cited that albumin has been widely used in patients with cirrhosis in an attempt to improve circulatory and renal functions. Nakamura et al. (2014) demonstrated that the administration of albumin significantly increased the serum levels of albumin in patients with liver cirrhotic disease.

\section{Conclusion}

The findings of the present study show that plasma cholinesterase level depends on the integrity of liver cells. If intact, the cholinesterase has normal or stable levels. Cholinesterase levels tend to decrease relatively with the grade liver of damage. Serum cholinesterase appears more stable and is not easily affected by medications that are given to cirrhotic patients. It can therefore be used as a marker for the diagnosis and prognosis of the synthesis power of the liver together with PT and albumin.

\section{REFERENCES}

Amanvermez R, Baydın A, Yardan T, Başol N, Günay M, 2010. Emergency laboratory abnormalities in suicidal patients with acute organophosphate poisoning. Turk J Biochem, 35(1): 29-34.

Bishop M, Edward E, 2010. Clinical Chemistry; sixth edition; Lippincott Williams and Willinks; Baltimore, Philadephia; 522, 238.

Bonis PA, Tong MJ, Blatt LM, Conrad A, Griffith JL, 1999. A predictive model for the development of hepatocellular carcinoma, liver failure, or liver transplantation for patients presenting to clinic with chronic hepatitis C. Am J Gastroenterol, 94(6): 1605-1612.

Botta F, Giannini E, Romagnoli P, Fasoli A, Malfatti F, Chiarbonello B, Testa E, Risso D, Colla G, Testa R, 2003. MELD scoring system is useful for predicting prognosis in patients with liver cirrhosis and is correlated with residual liver function: a European study. Gut, 52(1): 134-139.

Chen CY, Tsai WL, Lin PJ, Shiesh SC, 2011. The value of serum ischemia-modified albumin for assessing liver function in patients with chronic liver disease. Clin Chem Lab Med, 49(11): 1817-1821.

Doumas BT, Peters T, 1997. Serum and urine albumin: a progress report on their measurement and clinical significance. Clin Chim Acta, 258(1): 3-20.

Dufour DR, Lott JA, Nolte FS, Gretch DR, Koff RS, Seeff LB, 2000. Diagnosis and monitoring of hepatic injury. II. Recommendations for use of laboratory tests in screening, diagnosis, and monitoring. Clin Chem, 46(12): 2050-2068

Dufour DR, Lott JA, Nolte FS, Gretch DR, Koff RS, Seeff LB, 2000. Diagnosis and monitoring of hepatic injury. I. Performance characteristics of laboratory tests. Clin Chem, 46(12): 2027-2049.

Fishman WH, 1990. Alkaline phosphatase isoenzymes: recent progress. Clin Biochem, 23(2): 99-104.

Giannini EG, Testa R, Savarino V, 2005. Liver enzyme alteration: a guide for clinicians. CMAJ. 172(3): 367-379.

Green RM, Flamm S, 2002. AGA technical review on the evaluation of liver chemistry tests. Gastroenterology, 123(4): 1367-1384.

Kamath PS, Wiesner RH, Malinchoc M, Kremers W, Therneau TM, Kosberg CL, D'Amico G, Dickson ER, Kim WR, 2001. A model to predict survival in patients with end-stage liver disease. Hepatology, 33(2): 464-470.

Lee JS, 2012. Albumin for end-stage liver disease. Korean J Intern Med, 27(1): 13-19.

Lim EJ, Gow PJ, Angus PW, 2009. Endoscopic variceal ligation for primary prophylaxis of esophageal variceal hemorrhage in prelivertransplant patients. Liver Transpl, 15(11): 1508-13.

Matsuzaki S, Iwamura K, Itakura M, Katsunuma T, 1980. Abnormalities of serum cholinesterase isozyme in liver cirrhosis and hepatoma (Part II). Gastroenterol Jpn, 15(6): 543-9.

Moss DW, 1997. Physiochemical and pathophysiological factors in the release of membrane-bound alkaline phosphatase from cells. Clin Chim Acta, 257(1): 133-140.

Nakamura T, Sata M, Hiroishi K, Masaki N, Moriwaki H, Murawaki Y, Yatsuhashi H, Fujiyama S, Imawari M, 2014. Contribution of diuretic therapy with human serum albumin to the management of ascites in patients with advanced liver cirrhosis: A prospective cohort study. Mol Clin Oncol, 2(3): 349-355.

Potze W, Adelmeijer J, Porte RJ, Lisman T, 2015. Preserved clot formation detected by the Thrombodynamics analyzer in patients with cirrhosis. Thromb Res, 135(5): 1012-1016.

Pratt DS, Kaplan MM, 2000. Evaluation of abnormal liver-enzyme results in asymptomatic patients. N Engl J Med, 342(17):1266-1271.

Ramachandran J, Sajith KG, Priya S, Dutta AK, Balasubramanian KA, 2014. Serum cholinesterase is an excellent biomarker of liver cirrhosis. Trop Gastroenterol, 35(1): 15-20.

Rej R, 1989. Aminotransferases in disease. Clin Lab Med, 9(4): 667687

Rochling FA, 2001. Evaluation of abnormal liver tests. Clin Cornerstone, 3(6): 1-12.

Saxena P, Bihari C, Rastogi A, Agarwal S, Anand L, Sarin SK, 2013. Sonoclot signature analysis in patients with liver disease and its correlation with conventional coagulation studies. Adv Hematol, 2013:237351.

Schlaeger R, Haux D, Kattermann R, 1982. Studies on the mechanism of the increase in serum alkaline phosphatase activity in cholestasis: significance of the hepatic bile acid concentration for the leakage of alkaline phosphatase from rat liver. Enzyme, 28(1): 3-13.

Seeto RK, Fenn B, Rockey DC, 2000. Ischemic hepatitis: clinical presentation and pathogenesis. Am J Med, 109(2): 109-113.

Serra MA, Puchades MJ, Rodríguez F, Escudero A, del Olmo $\mathrm{JA}$, Wassel AH, Rodrigo JM, 2015. Clinical value of increased serum creatinine concentration as predictor of short-term outcome in decompensated cirrhosis. Scand J Gastroenterol, 39(11): 1149-1153.

Strahl S, Maier KP, 2006. Risk-classification in liver cirrhosis. Praxis (Bern 1994) 95(34):1275-1281.

Titcomb CP Jr, 2003. Liver function tests: what is the risk? J Insur Med, 35(1): 26-35.

Tripathi A, Tiwari B, Patil R, Khanna V, Singh V, 2015. The role of salivary caffeine clearance in the diagnosis of chronic liver disease. $J$ Oral Biol Craniofac Res, 5(1): 28-33.

Vanderlinde RE, 1986. Review of pyridoxal phosphate and the transaminases in liver disease. Ann Clin Lab Sci, 16(2): 79-93.

Velayudham LS, Farrell GC, 2003. Drug-induced cholestasis. Expert Opin Drug Saf, 2(3): 287-304. 
Wang J, Gao JX, Bai YZ, 2005. Patients with cirrhosis serum cholinesterase clinical research. Chin J Med Lab Sci, 28: 68.

Woreta TA, Alqahtani SA, 2014. Evaluation of abnormal liver tests. Med Clin North Am, 98(1):1-16.

Yanai M, Hoshino T, 2010. Pseudocholinesterase (ChE). Rinsho Byori, 116: $45-51$.

Zhou X, Tu ZG, 2003. Clinical Biological Chemical and Biological Chemical Inspection. 3rd edition. People's Medical Publishing House, Beijing, pp 325-328.
Citation: M ohamed NAA, Amanullah M, Amanvermez R, Ibrahim MA, Abbas M, 2017. Serum cholinesterase as liver function test in cirrhotic patients at Soba Teaching hospital, Khartoum, Sudan. Int Res J Med Med Sci, 5(3): 44-49. 